\title{
DAMPAK IHTIKAR TERHADAP MEKANISME PASAR DALAM PERSPEKTIF ISLAM
}

\section{IHTIKAR IMPACT ON MARKET MECHANISM IN ISLAMIC PERSPECTIVE}

\author{
Muhammad Deni Putra, Frida Amelia \\ Fakultas Ekonomi dan Bisnis Islam IAIN Batusangkar \\ Jl. Sudirman No. 137, Kuburajo, Lima Kaum, Batusangkar \\ email: mdeniputra@iainbatusangkar.ac.id,fridaamelia.19@gmail.com

\section{Darnela Putri} \\ Mahasiswa Program Pasca Sarjana Ekonomi Islam UII \\ Jalan Demangan Baru No. 24 Yogyakarta - 55281 \\ e-mail: darnelaputri96@gmail.com
}

Naskah diterima 28 Juli 2019, di-review 27 September 2019, disetujui 20 Desember 2019

\begin{abstract}
This article is intended to explore the impact of ihtikar on market mechanisms in Islamic perspective. It provides a clear conceptual description of the effects of deviant actions in the market mechanism, namely ihtikar actions. Then the concept can be used as an analysis for the role of government as a regulator of the market. This research is a library research with a qualitative approach. The analysis process will be described using the content analysis technique. The impact arising from the practice of ihtikar is the practice of ihtikar disrupting the smooth transactions in the market, where producers get huge profits while consumers suffer losses because producers take profits above the price they should. The practice of ihtikar will disrupt the market mechanism, where producers will then sell at a price higher than the normal price. It can be assumed the practice of ihtikar in trading includes acts that are very immoral and also inhumane, because such trade practices create many disadvantages for human life.
\end{abstract}

Keywords: Ihtikar, Impact, Market Mechanisms

\begin{abstract}
Abstrak: Artikel ini dimaksudkan untuk menelusuri dampak dari ihtikar terhadap mekanisme pasar dalam perspektif Islam. Kontribusi nyata dalam tulisan ini adalah memberikan gambaran konsep yang jelas mengenai akibat dari perbuatan yang menyimpang dalam mekanisme pasar yaitu perbuatan ihtikar. Kemudian konsep tersebut dapat dipergunakan sebagai analisis untuk peran pemerintah sebagai pembuat regulasi terhadap pasar. Penelitian ini merupakan penelitian kepustakaan (library reseach) dengan pendekatan kualitatif. Proses penganalisaan akan dideskripsikan dengan menggunakan tekhnik content analysis (analisa isi). Adapun dampak yang timbul akibat praktek ihtikar ini adalah Praktek ihtikar menganggu kelancaran transaksi di pasar, di mana produsen mendapatkan keuntungan yang sangat besar sementara konsumen menderita kerugian karena produsen mengambil keuntungan di atas dari harga yang seharusnya. Praktek ihtikar akan menyebabkan mekanisme pasar terganggu, di mana produsen kemudian akan menjual dengan harga yang lebih tinggi dari harga normal. Praktek ihtikar dalam perdagangan termasuk pada tindakan yang sangat tidak bermoral dan juga tidak manusiawi, karena praktik perdagangan semacam itu banyak menimbulkan madlarat bagi kehidupan manusia.
\end{abstract}

Kata Kunci: Ihtikar, Dampak, Mekanisme Pasar

\section{PENDAHULUAN}

$I$ slam selain bersifat syumuliyah (sempurna) juga harakiyah (dinamis). Sempurna karena
Islam merupakan agama penyempurna dari agama-agama sebelumnya dan syari'atnya mengatur seluruh aspek kehidupan, baik yang bersifat aqidah maupun muamalah. Dalam 
kaidah tentang muamalah, Islam mengatur segala bentuk perilaku manusia dalam berhubungan dengan sesamanya untuk memenuhi kebutuhan hidupnya di dunia. Termasuk di dalamnya adalah kaidah Islam yang mengatur tentang pasar dan mekanismenya. Tempat dimana penjual dan pembeli bertemu dan melakukan transaksi jual beli barang dan atau jasa dikatakan pasar. Pentingnya pasar dalam Islam tidak terlepas dari fungsi pasar sebagai wadah bagi berlangsungnya kegiatan jual beli. (Novi Indriyani Sitepu, Jurnal Hukum dan Ekonomi Syari'ah, Vol. 06, : 1)

Ibn Taimiyah merupakan salah seorang ilmuan Muslim yang secara mendetail membahas tentang mekanisme pasar dan jenis-jenis pasar. Menurut pemikiran Ibn Taimiyah, bahwa terjadinya fluktuasi harga pasar dipengaruhi oleh permintaan dan ketersediaan barang. Harga akan naik jika penawaran meningkat sementara persediaan menipis, begitupun sebaliknya. Hal ini sudah merupakan hukum alam, yang disebut dengan mekanisme pasar. (Syarial Dedi, Al Falah: Journal Of Islamic Economics, Vol. 3, No. 1, 2018, : 74-75.)

Pada dasarnya, ekonomi Islam menghendaki mekanismepasaryangbebastanpaadanyaintervensi. Harga wajar dan adil (fair price) adalah harga yang diperoleh berdasarkan kekuatan penawaran (supply) dan permintaan (demand). Hubungan antara pasar, pemerintah dan individu adalah sejajar. Namun, kenyataan yang ada dilapangan, pasar yang adil, dan tanpa adanya kedhaliman, seringkali tidak terjadi, sehingga Ekonomi Islam menegaskan bahwa mekanisme pasar dan penetapan harga perlu diatur untuk menegakkan keseimbangan pasar dan keadilan ekonomi dengan mempertimbangkan kepentingan para pihak yang terlibat di pasar.
Distorsi pasar merupakan bentuk penyimpangan yang menyebabkan terjadinya ketidakseimbangan di pasar yang harus diatur oleh pemerintah (pihak otoritas) lewat kebijakan intervensi yang menjadi wewenangnya. (Lukmanul Hakim, Ekomadania Volume 1. Nomor 1 Juli 2017,: 1)

Dalam fiqh Islam, distorsi penawaran (false supply) lebih dikenal sebagai ikhtikar, sedangkan distorsi pada permintaan (false demand) dikenal sebagai bai' najasy. (Adiwarman A. Karim, : 181182). Rasulullah telah melarang praktek ihtikar, yaitu secara sengaja menahan atau menimbun barang, terutama pada saat terjadinya kelangkaan, dengan tujuan untuk menaikan harga dikemudian hari. Akibat dari ihtikar ini masyarakat luas akan dirugikan oleh sekelompok yang lain. Agar harga dapat kembali ke posisi semula maka pemerintah dapat melakukan berbagai upaya menghilangkan penimbunan ini. (Ulfa Jamilatul Farida, Jurnal Ekonomi Islam La_Riba, Vol VI, No. 2, Desemeber 2012, : 265.)

Berdasarkan uraian di atas maka penulis tertarik untuk membahas lebih dalam tentang dampak yang ditimbulkan ihtikar dalam mekanisme pasar yang seharusnya berjalan sempurna, namun mengalami distorsi atau gangguan jika terjadi ihtikar. artikel ini penulis beri judul "Dampak Ihtikar Terhadap Mekanisme Pasar dalam Perspektif Islam".

\section{KERANGKA KONSEPTUAL}

\section{Konsep Ihtikar}

Ihtikar secara terminologi adalah jika seseorang membeli makanan pada saat harga mahal, kemudian ia menimbunnya untuk dijual 
dengan harga lebih mahal ketika kebutuhan terhadap makanan tersebut mendesak. Menimbun dalam bahasa Arab adalah ihtikar dari kata ihtikarayahtakiru yang bermakna secara bahasa adalah alhabsu (menahan) dan aljam'u (mengumpulkan) secara etimologi ialah perbuatan menimbun, pengumpulan (barang-barang) atau tempat untuk menimbun. (Fasiha Dan Muh. Ruslan Abdullah, Al-Amwal : Journal Of Islamic Economic Law September 2018, Vol. 3, No. 2, : 188.)

Ihtikar ini sering kali diterjemahkan sebagai monopoli dan/atau penimbunan. Padahal sebenarnya Ihtikar tidak monopoli dan/atau penimbunan. Dalam Islam, siapapun boleh berbisnis tanpa peduli apakah dia satu-satunya penjual (monopoli) atau ada penjual lain. Menyimpan stock barang untuk keperluan persediaanpun tidak dilarang dalam Islam. Jadi monopoli sahsah saja. Demikian pula menyimpan persediaan. Yang dilarang adalah Ihtikar, yaitu mengambil keuntungan di atas keuntungan normal dengan cara menjual lebih sedikit barang untuk harga yang lebih tinggi, atau istilah ekonominya monopoly's rent-seeking. Jadi dalam Islam, monopoli boleh. Sedangkan monopoly's rent-seeking tidak boleh. (Adiwarman A. Karim, : 185)

Pedagang dilarang melakukan ihtikar, yaitu melakukan penimbunan barang dengan tujuan spekulasi, sehingga ia mendapatkan keuntungan besar di atas keuntungan normal atau dia menjual hanya sedikit barang untuk mendapatkan harga yang lebih tinggi, sehingga mendapatkan keuntungan di atas keuntungan normal. Dalam ilmu ekonomi hal ini disebut dengan monopoly's rent seeking. Larangan ihtikar ini terdapat dalam Sabda Nabi SAW (Al-Mubarakafuri), Dari Ma'mar bin Abdullah bin Fadhlah, katanya, Aku mendengar Rasulullah Saw bersabda, "Tidak melakukan ihtikar kecuali orang yang bersalah (berdosa)". (H.R.Tarmizi).

Di kalangan ulama memang terdapat perbedaan tentang barang yang terlarang untuk dijadikan obyek ihtikar. Namun, tampaknya ada kesamaan persepsi tentang tidak bolehnya ihtikar terhadap kebutuhan pokok. Imam Nawawi dengan tegas mengatakan ihtikar terhadap kebutuhan pokok haram hukumnya. Pendapat An-Nawawi ini sangat rasional, karena kebutuhan pokok menyangkut hajat hidup orang banyak. Namun harus dicatat, bahwa banyak sekali terjadi pergeseran kebutuhan. Dulu mungkin suatu produk tidak begitu dibutuhkan dan tidak mengganggu kehidupan sosial, tetapi kini produk itu mungkin menjadi kebutuhan utama, misalnya minyak, obat-obatan, dsb. Karena itu kita tak boleh terjebak kepada klasifikasi barang yang tak boleh ditimbun dan barang yang boleh, tetapi perlu dirumuskan bahwa setiap penimbunan yang bertujuan untuk kepentingan spekulasi sehingga dampaknya mengganggu pasar dan sosial ekonomi, maka ia dilarang.

Rasulullah telah melarang praktek ihtikar, yaitu secara sengaja menahan atau menimbun barang, terutama pada saat terjadinya kelangkaan, dengan tujuan untuk menaikan harga dikemudian hari. Akibat dari ihtikar ini masyarakat luas akan dirugikan oleh sekelompok yang lain. Agar harga dapat kembali ke posisi semula maka pemerintah dapat melakukan berbagai upaya menghilangkan penimbunan ini.(Ulfa Jamilatul Farida, Jurnal Ekonomi Islam La_Riba, VolVI, No. 2, Desemeber 2012, : 265.)

Dampak lhtikar terhadap Mekanisme Pasar... || 185 


\section{Transaksi Kategori Ikhtikar}

Menurut Ain Rahmi dalam (Jurnal Ekonomi Bisnis dan Kewirausahaan 2015, Vol. 4, No. 2, : 182-183.) menyatakan bahwa suatu kegiatan masuk dalam ketegori ihtikar apabila tiga unsur berikut:

1. Terdapat dalam kegiatan tersebut untuk mengupayakan adanya kelangkaan barang baik dengan cara menimbun stock atau mengenakan entry barrier.

2. Menjual dengan harga yang lebih tinggi dibandingkan dengan harga sebelum munculnya kelangkaan.

Mengambil keuntungan yang lebih tinggi dibandingkan keuntungan sebelum komponen 1 dan 2 dilakukan.

\section{Dasar Hukum Ihktikar}

Adapun ayat yang dapat menjelaskan persolan mengenai ihtikar yaitu: QS. Al-Taubah ayat 34-35:

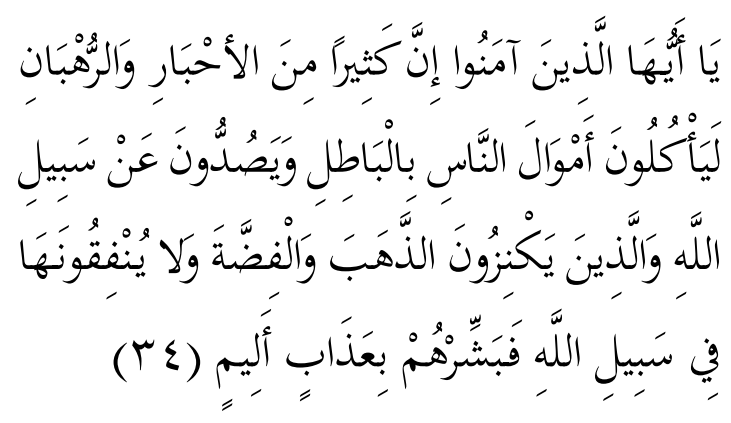

Hai orang-orang yang beriman, sesungguhnya sebahagian besar dari orang-orang alim Yahudi dan rahib-rahib Nasrani benar-benar memakan harta orang dengan jalan batil dan mereka menghalang-halangi (manusia) dari jalan Allah. Dan orang-orang yang menyimpan emas dan perak dan tidak menafkahkannya pada jalan Allah, maka beritahukanlah kepada mereka, (bahwa mereka akan mendapat) siksa yang pedih

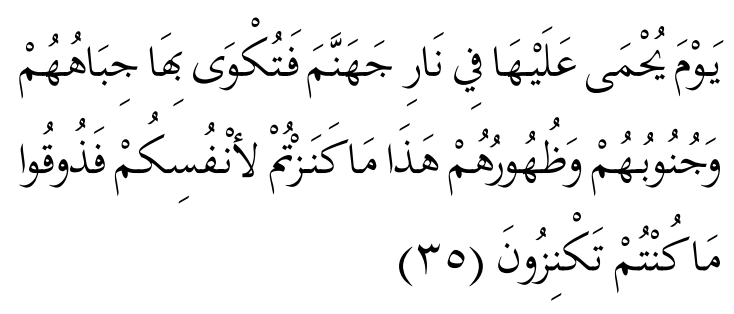

Pada hari dipanaskan emas perak itu dalam neraka jahannam, lalu dibakar dengannya dahi mereka, lambung dan punggung mereka (lalu dikatakan) kepada mereka: "Inilah harta bendamu yang kamu simpan untuk dirimu sendiri, maka rasakanlah sekarang (akibat dari) apa yang kamu simpan itu"

Asbabul Nuzul ayat ini adalah diriwayatkan dari Ibnu Abbas bahwa permulaan ayat ini turun berkenaan dengan para pendeta dari golongan ahli Kitab yang mengambil suap dari pengikutnya. Penghujung ayat ini turun berkenan dengan ahli kitab dan kaum muslim yang sering menimbun harta benda. Intisari dari ayat ini adalah kebiasaan dari orang-orang yahudi, baik para ulama maupun rahib mereka, melakukan kebatilan, yaitu mencari harta benda dengan cara yang tidak selayaknya dan menghalanghalangi orang-orang yang akan beriman ataupun orang-orang yang telah beriman untuk beribadah kepada Allah. (Fasiha Dan Muh. Ruslan Abdullah, Al-Amwal : Journal Of Islamic Economic Law September 2018, Vol. 3, No. 2, : 190)

Rasulullah telah melarang praktek ihtikar, yaitu secara sengaja menahan atau menimbun (hoarding) barang, terutama pada saat terjadi kelangkaan, dengan tujuan untuk menaikkan harga di kemudian hari. Pengharaman ini didasarkan pada beberapa hadits Nabi, terdapat dalam jurnal (Nikmatul Masruroh, Interest, Vol.13, No. 1 Oktober 2015, : 85) antara lain: 
"Diriwayatkan dari Umar ra: bahwa Rasulullah SAW bersabda: Orangyang berdagang akan mendapatkan rezeki dan orang yang memonopoli akan terlaknat"

"Diriwayatkan Abi Hurairah bahwa Rasulullah SAW bersabda: Barang siapa yang memonopoli untuk meninggikan harga barang bagi orangorang Muslim, maka ia bersalah

"Diriwayatkan dari Said bin al Musyyab dan Ma'mar bin Abdullah al Adawi bahwa Rasulullah s.a.w bersabda: "Tidaklah orang melakukan ihtikar itu melainkan berdosa"

\section{METODE PENELITIAN}

Artikel ini dimaksudkan untuk menelusuri dampak dari ihtikar terhadap perekonomian dalam perspektif Islam. Kontribusi nyata dalam tulisan ini adalah memberikan gambaran konsep yang jelas mengenai akibat dari perbuatan yang menyimpang dalam mekanisme pasar yaitu perbuatan ihtikar. Kemudian konsep tersebut dapat dipergunakan sebagai analisis untuk peran pemerintah sebagai pembuat regulasi terhadap pasar. Penelitian ini merupakan penelitian kepustakaan (library reseach) dengan pendekatan kualitatif. Proses penganalisaan akan dideskripsikan dengan menggunakan tekhnik content analysis (analisa isi).

\section{PEMBAHASAN DAN HASIL}

\section{Dampak Ihktikar}

Dalam konteks syariat, interaksi pemenuhan kebutuhan hidup disebut dengan muamalah. Dalam konteks ini, interaksi yang terjadi memiliki batasan-batasan yang harus dijaga. Terutama dalam persoalan transaksi. Prinsip yang sangat mendasar dalam hal pemenuhan kebutuhan antar para pihak adalah adanya keridaan baik secara lahir maupun batin dan syariat memberikan batasan-batasan. (Taufiq, Jurnal Ilmiah Syari'Ah, Volume 15, Nomor 1, Januari-Juni 2016, : 1).

Praktek ihtikar menganggu kelancaran transaksi di pasar, di mana produsen mendapatkan keuntungan yang sangat besar sementara konsumen menderita kerugian karena produsen mengambil keuntungan di atas dari harga yang seharusnya. Praktek ihtikar ini hanyalah rekayasa dari pelaku di mana seolah-olah stok barang sedikit, maka sesuai dengan hukum demand dan supply, ketika supply berkurang sedangkan permintaan tetap maka harga akan menjadi naik. Ketika harga telah naik itulah kemudian pelaku menjual barang barang yang telah mereka timbun sehingga keuntungan yang mereka perolehpun berlipat ganda dari yang semestinya. (Gusniarti, Jurnal Etikonomi Vol. 14 No. 2 Oktober 2015, : 166).

Praktek ihtikar akan menyebabkan mekanisme pasar terganggu, dimana produsen kemudian akan menjual dengan harga yang lebih tinggi dari harga normal. Penjual akan mendapatkan untung besar (monopoly's rent), sedangkan konsumen akan menderita kerugian. Jadi, akibat ihtikar maka masyarakat luas dirugikan oleh sekelompok kecil yang lain. Agar harga kembali pada posisi harga pasar maka pemerintah dapat melakukan berbagai upaya menghilangkan penimbunan ini (misalnya dengan penegakan hukum), bahkan juga dengan intervensi harga. (Nikmatul Masruroh, Interest, Vol.13, No. 1 Oktober 2015., : 85).

Ihtikar dalam perspektif hukum Islam merupakan praktik perdagangan yang sangat tidak 
bermoral dan juga tidak manusiawi, karena praktik perdagangan semacam itu banyak menimbulkan mudharat bagi kehidupan manusia. Di antara mudharat yang bias ditimbulkannya adalah ad- dlaiq (kesusahan) bagi masyarakat di dalam mendapatkan kebutuhan pangan khususnya dalam hal-hal yang bersifat dlaruri (primer). Dalam hal penimbunan barang-barang pangan yang bersifat primer dan berakibat kepada kondisi ad- dlaiq tadi bisa jadi karena barang-barang itu secara nominal terbatas dan bisa juga karena harganya sangat tinggi, tidak diragukan lagi bahwa hukumnya haram. Dengan demikian tidak ada alasan bagi muhtakir yang dengan tindakannya itu mengakibatkan maslahat orang banyak terabaikan. (Lukman Hakim, Jurnal Darussalam: Jurnal Pendidikan, Komunikasi Dan Pemikiran Hukum Islam Vol. Vii, No 2: April 2016, : 329).

Kedua prinsip hukum ini harus dijaga agar keseimbangan dapat tecipta. OIeh sebab itu, dapat dikatakan semua bentuk penimbunan yang berakibat dlaiq adalah dilarang (haram) hukumnya. Namun. Barangkali tingkat keharamannya tentulah berbeda tergantung kepada apakah hal itu menyangkut dlaruri, haji, atau tahcini. Apabila penimbunan barang- barang yang bersifat dlaruri tingkat keharaman lebih tinggi dibandingkan dengan haji, dan tahsini. (Lukman Hakim, Jurnal Darussalam: Jurnal Pendidikan, Komunikasi Dan Pemikiran Hukum Islam Vol. Vii, No 2: April 2016, : 329).

Analisis Peran Pemerintah Terhadap Praktek Ikhtikar

Pelaksanaan tugas pemerintah dalam mengawasi jalannya aktivitas pasar memegang

188| Muhammad Deni Putra, Frida Amelia peranan yang sangat penting untuk terciptanya tertip pasar, tertib harga, tertib takaran dan timbangan serta tata kelola pasar sehingga menjadikan pasar sebagai tempat yang benarbenar ideal dan nyaman untuk melakukan kegiatan jual beli. Kondisi ini merupakan kondisi yang sangat didambakan oleh semua pihak. Masyarakat selaku konsumen menginginkan adanya keadilan dalam transaksi jual beli, pemerintah selaku pelaksana tugas pengawasan terhadap pasar menginginkan adanya kepatuhan pedagang dalam melaksanakan ketentuan dan peraturan yang berkaitan dengan takaran dan timbangan, tata kelola pasar dan lain-lain. Sehingga tugas pemerintah dalam melakukan pengawasan terhadap pasar dapat dicapai. (Mahadir, Jurnal As-Salam, 2(1) Januari - April 2018, : 76).

Ketika terjadi kegagalan pasar (distorsi pasar), maka pemerintah harus turun tangan. memastikan mekanisme pasar yang adil kembali bekerja. Menurut Islam negara memiliki hak untuk melakukan intervensi dalam kegiatan ekonomi baik itu dalam bentuk pengawasan, pengaturan maupun pelaksanaan kegiatan ekonomi yang tidak mampu dilaksanakan oleh masyarakat. Dalam konsep ekonomi islam, cara pengendalian harga ditentukan oleh penyebabnya. Bila penyebabnya adalah perubahan pada Genuine demand dan Genuine supply, Maka mekanisme pengendalian dilakukan melalui market intervention (kontrol harga). Sedangkan bila penyebabnya adalah distorsi Genuine demand dan Genuine supply, maka mekanisme pengendalian dilakukan melalui penghilangan distorsi termasuk penentuan price intervention untuk mengembalikan harga pada keadaan sebelum distorsi. (Lukmanul Hakim, :12). 
Dalam konteks ini. kaum muslimin pernah mengalami harga-harga naik di Madinah yang disebabkan faktor yang genuine. Untuk mengatasi hal tersebut khalifah Umar bin Khattab ra melakukan market intervention. Sejumlah besar barang diimpor dari Mesir ke Madinah. Jadi intervensi langsung dilakukan melalui jumlah barang yang ditawarkan. Intervensi pasar telah dilakukan di zaman Rasulullah dan Khulafaur Rasyidin. Saat itu harga gandum di Madinah naik, maka pemerintah melakukan impor gandum dari Mesir. Selama kekuatan pasar berjalan berjalan rela sama rela tanpa ada yang melakukan distorsi, maka Rasulullah SAW menolak untuk melakukan price intervention. (Muhammad Birusman Nuryadi, Mazahib Vol. IV, No. 1, Juni 2007., :97).

Menurut Ibnu Taimiyah dalam (Lukmanul Hakim.,:13). Keabsahan pemerintah dalam menetapkan kebijakan intervensi dapat terjadi pada situasi dan kondisi sebagai berikut:

1. Produsen tidak mau menjual produknya kecuali pada harga yang lebih tinggi dari pada harga umum pasar, padahal konsumen membutuhkan produk tersebut.

2. Terjadi kasus monopoli (penimbunan).

3. Terjadi keadaan Al-Hasr (pemboikotan), di mana distribusi barang hanya terkonsentrasi pada satu penjual atau pihak tertentu. Penetapan harga di sini untuk menghindari penjualan barang tersebut dengan harga yang ditetapkan sepihak dan semena-mena oleh pihak penjual tersebut.

4. Terjadi koalisi dan kolusi antar penjual (kartel) di mana sejumlah pedagang sepakat untuk melakukan transaksi di antara mereka, dengan harga di atas ataupun di bawah harga normal.
5. Produsen menawarkan produknya pada harga yang terlalu tinggi menurut konsumen, sedangkan konsumen meminta pada harga yang terlalu rendah menurut produsen.

Mengenai regulasi harga menurut Ibn Taimiyyah, harga barang naik karena kekuatan pasar, bukan karena ketidaksempurnaan pasar tersebut. Kemudian beliau juga mengatakan bahwa pengaturan harga diperlukan untuk mencegah pedagang menjual makanan atau barang dengan sesuka hati dan hanya menjual kepada kelompok tertentu saja. (Ichsan Iqbal, Jurnal Khatulistiwa - Journal Of Islamic Studies, Volume 2 Nomor 1 Maret 2012, : 8).

Secara umum, jumhur ulama sepakat bahwa penetapan harga adalah kebijakan yang tidak dianjurkan oleh ajaran Islam jika pasar dalam situasi normal. (Pusat Pengkajian Dan Pengembangan Ekonomi Islam (P3EI) Univeritas Islam Indonesia Yogyakarta Atas Kerja Sama Dengan Bank Indonesia, : 337). Namun jika pasar dalam situasi tidak normal, maka perlu adanya kebijakan dari pemerintah. Adapun tujuan adanya intervensi pasar yang dilakukan oleh pemerintah menurut Ibnu Qudamah al Maqdisi adalah sebagai berikut:

1. Intervensi harga menyangkut kepentingan masyarakat.

2. Untuk mencegah ikhtikar dan ghaban faa-hisy (mengambil keuntungan diatas keuntungan normal dan menjual diatas harga pasar).

3. Untuk melindungi kepentingan masyarakat yang lebih luas.

(Ain Rahmi :182) Menyatkan bahwa regulasi harga (bagian dari intervensi Pemerintah) memiliki 3 fungsi, yaitu

Dampak lhtikar terhadap Mekanisme Pasar... || 189 
1. Fungsi ekonomi (berhubungan dengan peningkatan produktivitas dan peningkatan pendapatan masyarakat miskin melalui alokasi dan relokasi sumber daya ekonomi),

2. Fungsi sosial (mempersempit kesenjangan antara masyarakat kaya dan masyarakat miskin),

3. Fungsi moral (upaya menegakkan nilai-nilai Islami dalam aktivitas perekonomian).

Pemerintah sangatlah berperan besar dalam stabilitas pasar dengan ikut campur tangan dalam perekonomian pasar maka di pasar akan stabil dalam perputarannya. Dengan berbagai metode konsep yang ideal dari pemerintah untuk menghadang pelaku monopoli. Dengan adanya campur tangan pemerintah maka stabilitas pasar akan selalu seimbang antara para pelaku ekonomi. (Indra Hidayatullah, Iqtishoduna Vol. 8 No. 1 April 2019, : 207).

\section{PENUTUP}

Pada dasarnya, ekonomi Islam menghendaki mekanisme pasar yang bebas tanpa adanya intervensi. Harga wajar dan adil (fair price) adalah harga yang diperoleh berdasarkan kekuatan penawaran (supply) dan permintaan (demand). Namun, kenyataan yang ada dilapangan, pasar yang adil, dan tanpa adanya kedhaliman, seringkali tidak terjadi, sehingga Ekonomi Islam menegaskan bahwa mekanisme pasar harus diatur oleh pemerintah (pihak otoritas) lewat kebijakan intervensi yang menjadi wewenangnya.

Dalam fiqh Islam, distorsi penawaran (false supply) lebih dikenal sebagai ikhtikar yaitu secara sengaja menahan atau menimbun barang, 190 || Muhammad Deni Putra, Frida Amelia terutama pada saat terjadinya kelangkaan, dengan tujuan untuk menaikan harga dikemudian hari. Adapun dampak yang timbul akibat praktek ihtikar ini adalah Praktek ihtikar menganggu kelancaran transaksi di pasar, di mana produsen mendapatkan keuntungan yang sangat besar sementara konsumen menderita kerugian karena produsen mengambil keuntungan di atas dari harga yang seharusnya. Praktek ihtikar akan menyebabkan mekanisme pasar ter-ganggu, dimana produsen kemudian akan menjual dengan harga yang lebih tinggi dari harga normal. Praktek ihtikar dalam perdagangan termasuk pada tindakan yang sangat tidak bermoral dan juga tidak manusiawi, karena praktik perdagangan semacam itu banyak menimbulkan madlarat bagi kehidupan manusia.

Rasulullah telah melarang praktek ihtikar, yaitu secara sengaja menahan atau menimbun barang, terutama pada saat terjadinya kelangkaan, dengan tujuan untuk menaikan harga dikemudian hari. Praktek ihtikar akan menyebabkan mekanisme pasar terganggu, dimana produsen kemudian akan menjual dengan harga yang lebih tinggi dari harga normal. Penjual akan mendapatkan untung besar (monopoly's rent), sedangkan konsumen akan men-derita kerugian.

Maka perlu intervensi dari pemerintah untuk mengatur pihak yang terlibat dalam pasar dan juga pemerintah sebagai lembaga yang mempunyai otorias terhadap mekanise pasar. Hal ini juga ditegaskan oleh Ekonomi Islam bahwa mekanisme pasar harus diatur oleh pemerintah (pihak otoritas) lewat kebijakan intervensi yang menjadi wewenangnya. 


\section{DAFTAR KEPUSTAKAAN}

Karim, Adiwarman A., 2007, Ekonomi Mikro Islami, Jakarta: PT Raja Grafindo Persada.

Dedi, Syarial., 2018, "Ekonomi Dan Penguasa (Pemikiran Ibn Taimiyah Tentang Mekanisme Pasar)", Al Falah: Journal of Islamic Economics, Vol. 3, No. 1, 2018.

Farida, Ulfa Jamilatul., 2012, "Telaah Kritis Pemikiran Ekonomi Islam Terhadap Mekanisme Pasar Dalam Konteks Ekonomi Islam Kekinian", Jurnal Ekonomi Islam La_ Riba, Vol VI, No. 2, Desember 2012.

Fasiha Dan Muh. Ruslan Abdullah., 2018, "Analisis Hukum Ekonomi Islam Terhadap Praktek Ihtikar", Al-Amwal : Journal Of Islamic Economic Law September 2018, Vol. 3, No. 2. Gusniarti., 2015, “Distorsi Pasar Dalam Proses Transaksi Sekuritas Syariah Di Pasar Sekunder", Jurnal Etikonomi Vol. 14 No. 2 Oktober 2015.

Hakim, Lukman., 2016, "Ihtikar dan Permasalahannya Dalam Perspektif Hukum Islam", Jurnal Darussalam: Jurnal Pendidikan, Komunikasi Dan Pemikiran Hukum Islam Vol. VII, No 2: 320-330. April 2016.

Hakim, Lukmanul., 2017, "Distorsi Pasar Dalam Pandangan Ekonomi Islam", Ekomadania Volume 1. Nomor 1. Juli 2017.

Hidayatullah, Indra., 2019, "Peran Pemerintah Dalam Stabilitas Ekonomi Pasar", Iqtishoduna Vol. 8 No. 1 April 2019.
Iqbal, Ichsan., 2012, "Pemikiran Ekonomi Islam Tentang Uang, Harga Dan Pasar", Jurnal Khatulistiwa - Journal Of Islamic Studies, Volume 2 Nomor 1 Maret 2012.

Mahadir., 2018, " Peranan Pemerintah Dalam Mengawasi Pasar Perspektif Ekonomi Islam", Jurnal As-Salam, 2(1) Januari - April 2018.

Masruroh , Nikmatul., 2015, "Larangan Ihtikar Di Indonesia (Kajian Tentang Efektifitas UU Anti Monopoli di Indonesia)", Interest, Vol.13, No. 1 Oktober 2015

Nuryadi, Muhammad Birusman., 2007, "Harga Dalam Perspektif Islam", Mazahib Vol. IV, No. 1, Juni 2007.

Pusat Pengkajian Dan Pengembangan Ekonomi Islam (P3EI) Univeritas Islam Indonesia Yogyakarta Atas Kerja Sama Dengan Bank Indonesia., 2008, Ekonomi Islam, Jakarta: PT Raja Grafindo Persada.

Rahmi, Ain., 2015, “Mekanisme Pasar dalam Islam”, Jurnal Ekonomi Bisnis dan Kewirausahaan 2015, Vol. 4, No. 2, 177-192.

Sitepu, Novi Indriyani., Model Sistem Pengawasan Pasar Berlandaskan Ekonomi Syariah, Jurnal Hukum dan Ekonomi Syari'ah, Vol. 06.

Taufiq., 2016, “Tadlis Merusak Prinsip 'Antaradhin Dalam Transaksi”, Jurnal Ilmiah Syari'Ah, Volume 15, Nomor 1, Januari-Juni 2016.

Dampak Ihtikar terhadap Mekanisme Pasar... | 191 